\title{
Investigation on the transport properties of chlorides in concrete (I) Identification of ITZ
}

\author{
$T_{I A N} \mathrm{Ye}^{1, *}, J_{N} \mathrm{Xianyu}^{1}$, and $\operatorname{JIN}$ Nanguo $^{1}$ \\ ${ }^{1}$ College of Civil Engineering and Architecture, Zhejiang University, Hangzhou 310058, China
}

\begin{abstract}
Concrete is a multiphase composite material, in which the mortar, aggregate and interfacial transition zone (ITZ) have important influence on the chloride ions transport. In this research, the thickness ITZ was measured and the concentration distribution of chloride ions in concrete was obtained through electron microprobe analysis. The experiment results that the thickness of ITZ follows a normal distribution and the size of aggregate shows no clear influence on the thickness of ITZ.
\end{abstract}

\section{INTRODUCTION}

Concrete is a multiphase material consisting of aggregate, interfacial transition zone (ITZ) and mortar matrix. Each phase is believed to have significant impact on the chloride ions diffusion. Shah[1] pointed out that the influence of aggregate on concrete permeability included four kinds of effects, the dilution effect, tortuosity effect, ITZ effect and percolation effect. And ITZ has been proved to be of great importance for the chloride ions diffusion in concrete[2]. The thickness of ITZ is a critical parameter for the analysis of chloride ions diffusion in concrete[3]. Although a reasonable range has been provided for thickness of ITZ through different investigation, an appropriate chosen of their values in a specific concrete is still the priority for an accurate analysis of chloride ions diffusion[4].

In this research, the thickness of ITZ in concrete was measured by electron probe technique. And a statistical analysis was conducted to characterize the distribution of ITZ.

\section{EXPERIMENT PREPARATION}

\subsection{Materials}

The cement used in this research was normal Portland cement with a grade of PI52.5. The sand was natural quartz sand with a fineness modulus of 1.6 and water was tap water. For both concrete and mortar, the water to cement ratio was 0.74 and the mass ratio of sand to cement was 2. For concrete, the volume fraction of coarse aggregates was $39.8 \%$. The ITZ was produced by embedding rod-shaped aggregates into mortar matrix. Rod-shaped aggregates were the core out of a limestone. Three kinds of rod-shaped aggregates were employed in this research with the diameter of $10 \mathrm{~mm}, 7 \mathrm{~mm}$ and $5 \mathrm{~mm}$ respectively. The length of the rod-shaped aggregates was $70 \mathrm{~mm}$. The aggregate area at a cross section of a specimen can be characterized through the Fuller aggregate gradation and volume fraction accordingly.

\subsection{Electron microprobe analysis}

Before electron microprobe analysis, the specimen was placed into a plexiglass pipe with the inner dimension of $60 \mathrm{~mm} \times 60 \mathrm{~mm} \times 50 \mathrm{~mm}$. Then the high flowable epoxy resin was filled into the gap between specimen and plexiglass pipe. Once the epoxy resin solidified, the specimen was cut transversely by a precision cutting machine. The thickness of the test sample was $5 \mathrm{~mm}$. Thereafter, the sample was immerged in a beaker full of alcohol. Then the beaker, as well as the sample, was put in JP-010T ultrasonic cleaner to remove impurities and dust on the cutting surface. The ultrasonic cleaning was totally performed three times, lasting at least 5 minutes at each time. Then the dried sample was coated with carbon film in JEE-420 vacuum coater to finish the sample preparation. Finally, a microscopic observation and element mapping were conducted with JXA-8100 electron microprobe analyzer. The carbon coated sample are shown in Fig.1.

Totally 30 backscattering images of ITZ around the aggregate surface were collected randomly. All images were taken at $250 \times$ magnification and the area covered by the images was $480 \times 384 \mu \mathrm{m}$. A high-resolution backscattering image can precisely reveal the mineral content distribution on the surface of the sample and represent the microstructure in details. As shown in Fig.2, the phases, i.e., the aggregate, sand, pores, unreacted cement and reacted cement paste matrix can all be identified through the grey level. It is also visually recognizable that there exists a dark region, ITZ, lying around the aggregate which implies this region is highly

* Corresponding author: cetianye@zju.edu.cn 
porous. In this research, a line scan for element of both $\mathrm{Si}$ and $\mathrm{Ca}$ was conducted vertically from aggregate to cement paste matrix, covering the ITZ. The length of the scan path was $500 \mu \mathrm{m}$, and two line-scans were carried out in each backscattering image. The area scan conducted by electron microprobe analyzer was applied to investigate the two-dimensional diffusion of chloride ions in concrete.

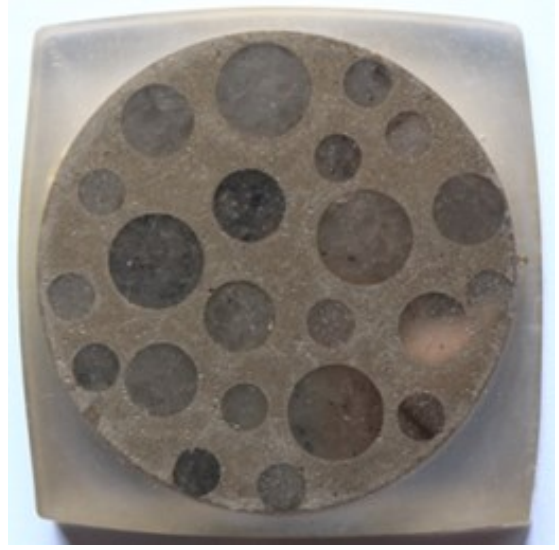

Fig.1 Carbon coated sample

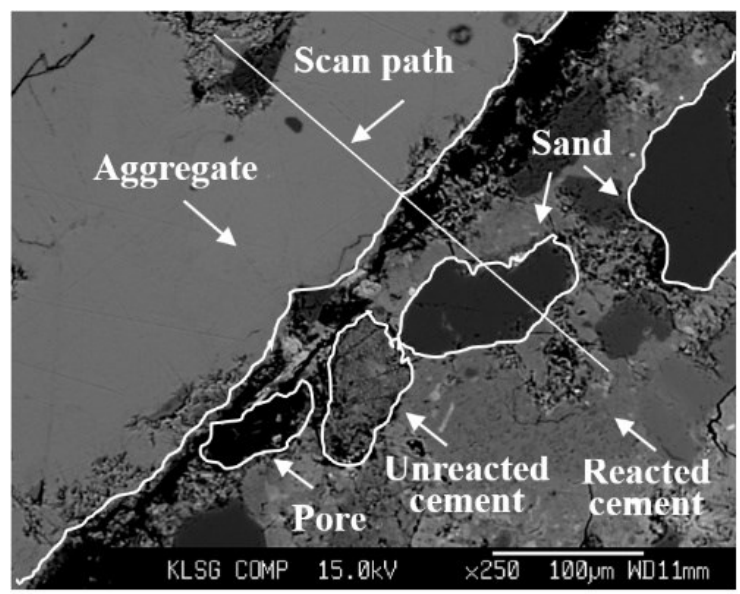

Fig.2 Backscattering image of the sample

\section{EXPERIMENT RESULTS}

It is well known that ITZ has a higher $w / c$ ratio at the early stage of hydration process. Ions with a relatively high mobility in cement paste solution, such as $\mathrm{Ca} 2+$, $\mathrm{Al} 3+$ and SO42-, tend to diffuse into the more porous ITZ due to the higher concentration gradients[5]. Therefore, a noticeable fluctuation of silicon and calcium content is always recognized from ITZ in comparison with cement paste matrix. This phenomenon can be proved by one of the line scans at ITZ, as shown as Fig.3.

Several researchers have used electron microprobe analysis to study the $\mathrm{Ca} / \mathrm{Si}$ ratio with ITZ and bulk cement paste[6-7]. It is theoretically and experimentally proved that the $\mathrm{Ca} / \mathrm{Si}$ ratio will settle down gradually at a certain distance from the surface of aggregate in a value about 5 or 6 approximately. While in this research, as there is no $\mathrm{Si}$ content in the rod-shape aggregate, so the
$\mathrm{Ca} / \mathrm{Si}$ ratio will be much higher than its reasonable range. Therefore, the thickness of ITZ is quantitatively assessed from $\mathrm{Si} / \mathrm{Ca}$ ratio instead of $\mathrm{Ca} / \mathrm{Si}$ ratio. It should also be emphasized that the measured ITZ prefers to the zone around the rod-shape aggregate. The thickness of ITZ around the sand is much smaller than that around aggregate, as shown as Fig.3(a). Furthermore, the diffusion of chloride in ITZ around sand is considered in the effective diffusion of mortar matrix.

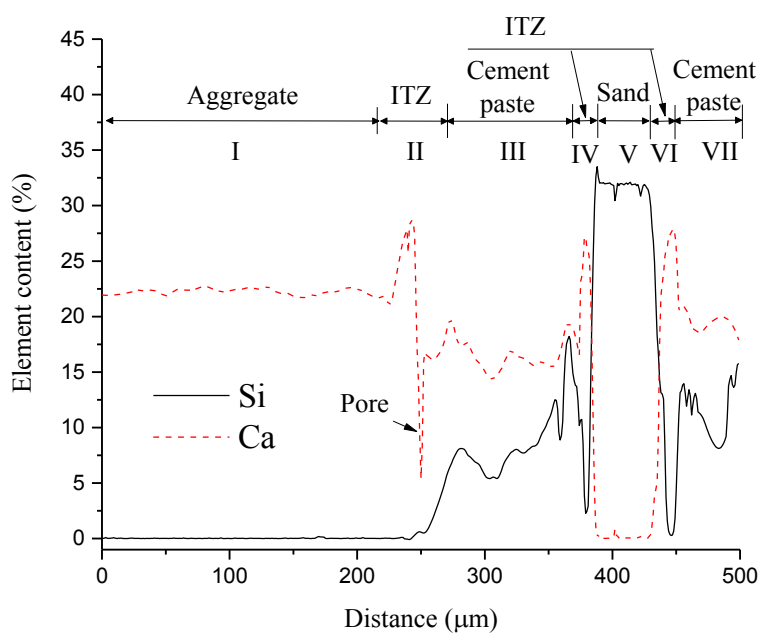

(a) Element content along the line scan path

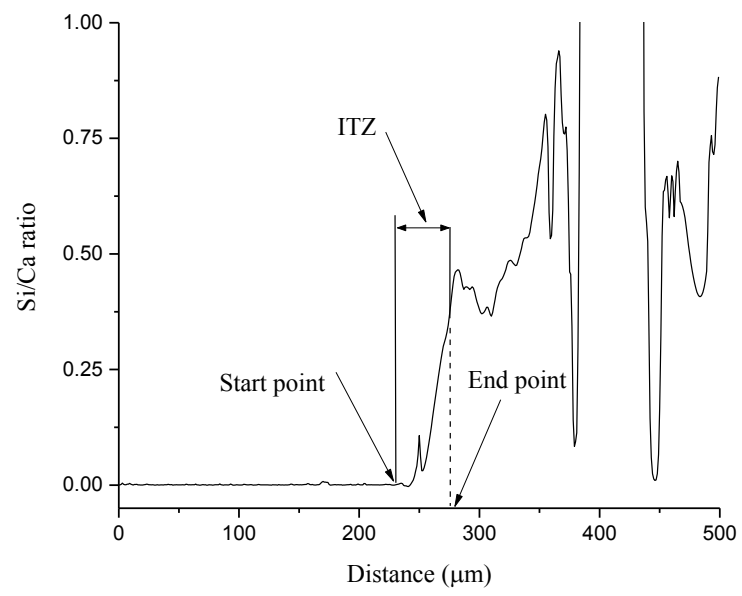

(b) $\mathrm{Si} / \mathrm{Ca}$ along the line scan path

Fig.3 Line scan on $\mathrm{Ca}$ and $\mathrm{Si}$ at ITZ

As shown in Fig.3(b), the $\mathrm{Si} / \mathrm{Ca}$ ratio is close to 0 before $229 \mu \mathrm{m}$ along the scan path which corresponds to rod-shape aggregate. Then a slight variation of $\mathrm{Si} / \mathrm{Ca}$ ratio indicates that some hydration products generate and deposit at the surface of aggregate. So the start point of ITZ can be marked by the small variation. The boundary of ITZ, in previous research, is always determined as an outline paralleled to the surface of aggregate, encircling a region in which the porosity is significantly greater, by a factor of $10 \%$ or $5 \%$, than the bulk porosity of cement paste. Analogously, the end point of ITZ is specified as the position at which the $\mathrm{Si} / \mathrm{Ca}$ ratio is $10 \%$ lower than the average value at bulk cement paste. As demonstrated in Fig.3(b), the thickness of ITZ is $40.5 \mu \mathrm{m}$ which can be 
easily calculated through the covered length from start point to end point.

In this research, The ITZs around the rod-shape aggregates with the diameter of $5 \mathrm{~mm}, 7 \mathrm{~mm}$ and $10 \mathrm{~mm}$ were all inspected. The measured thickness of ITZs are plotted against the frequency, as represented in Fig.4.

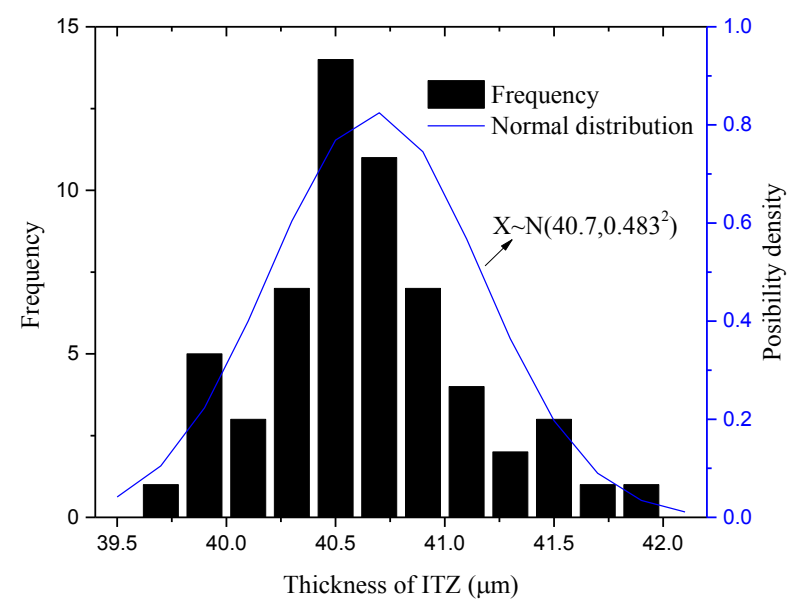

Fig.4 Distribution of ITZ thickness

It can be concluded from Fig. 4 that the thickness of ITZ concentrates around $40.5 \mu \mathrm{m}$ and descends gradually on both sides. A statistical analysis implies that the thickness of ITZ generally follows the normal distribution. The mean value of all the measured results are $40.7 \mu \mathrm{m}$. Actually, different researchers provided different estimations on the range of ITZ thickness, which depends on the experiment technologies and analyzing models. Basheer and Kropp gave a broad assessment as the ITZ ranges from 0 to $100 \mu \mathrm{m}[8]$. While most of the investigations believed that the thickness of ITZ was more specific between 10 and $50 \mu \mathrm{m}[9]$. Through SEM techniques, this value was furtherly narrowed down as $40-50 \mu \mathrm{m}[10]$. It is clear that the measured result using microprobe analysis is in great accordance with previous research. Meanwhile the average ITZ thickness for rod-shape aggregate with the diameter of $5 \mathrm{~mm}, 7 \mathrm{~mm}$ and $10 \mathrm{~mm}$ is $40.9 \mu \mathrm{m}, 40.6 \mu \mathrm{m}$ and $41.1 \mu \mathrm{m}$, respectively. There exists no clear difference between the thickness of ITZs for aggregates of different size. This phenomenon is also in well agreement with previous research as the thickness of ITZ is mainly determined by the median size of cement particle rather than the size of aggregate[11].

\section{CONCLUSIONS}

In this research, an electron microprobe technique was applied to quantitatively characterize the properties of ITZ.

The element analysis indicates that there exists a concentration gradient at the region surrounding the aggregate and the $\mathrm{Si} / \mathrm{Ca}$ ratio is used to identify ITZ accordingly. A statistical anlysis shows that the thickness of ITZ in this specimen follows a normal distribution. Besides, the diameter of rod-shape aggregate has no clear influence on the thickness of ITZ. Based on a parallel diffusion model, the difussivity of ITZ deduced from one-dimensional diffusion test is 40.7 times higher than mortar matrix.

This research is financially supported by National Key Basic Research Program of China (973 program) (Grant No. 2015CB655103) and National Natural Science Foundation of China (Grant No. 51320105013, 51378012).

\section{REFERENCES}

1. Shah S P. High performance concrete: Past, present and future, in: C.K.Y. Leung, Z. Li, J.T. Ding (Eds.), High Performance Concrete-Workability, Strength and Durability[C], Hong Kong University of Science and Technology, Hong Kong, 2000, pp. 3 -29 .

2. Garboczi E J, Bentz D P. Modelling of the microstructure and transport properties of concrete [J]. Construction and Building Materials, 1996, 10(5): 293-300.

3. Ollivier J P, Maso J C, Bourdette B. Interfacial transition zone in concrete[J]. Advanced Cement Based Materials, 1995, 2 (1): 30- 48.

4. Winslow D N, Cohen M D, Bentz D P, Snyder K A, Garboczi EJ. Percolation and pore structure in mortars and concrete[J]. Cement and Concrete Research, 1994, 24 (1): 25- 37.

5. Bentz D P, Garboczi E J . Computer modelling of interfacial transition zone microstructure and properties[J]. Materials and Structures, 1999: 349385.

6. Chen ZY, Odler I. The interfacial zone between marble and tricalcium silicate paste[J]. Cement and Concrete Research, 1987, 17 (5): 784-792.

7. Larbi JA, Bijen JMJM. Effects of water-cement ratio, quantity and fineness of sand on the evolution of lime in set Portland cement system[J]. Cement and Concrete Research, 1990, 20 (5): 783-794.

8. Basheer L, Kropp J. Assessment of the durability of concrete from its permeation properties: a review[J]. Construction and building materials, 2001, 15(2):93103.

9. Scrivener K L, and Nemati K M. The percolation of pore space in the cement paste aggregate interfacial zone of concrete[J]. Cement and Concrete Research, 1996, 26(1): 35-40.

10. Bentz D P, Stutzman P E, Garboczi E J. Experimental and simulation studies of the interfacial zone in concrete[J]. Cement and Concrete Research, 1992, 22 (5): 891-902.

11. Scrivener K L, Crumbie A K, Laugesen P. The interfacial transition zone (ITZ) between cement paste and aggregate in concrete[J]. Interface Science, 2004, 12 (4): 411-421. 